\title{
Absorptive and motor components of the antidiarrhoeal action of loperamide: an in vivo study in pigs
}

V Théodorou, J Fioramonti, T Hachet, L Buéno

\begin{abstract}
The effects of loperamide $(0.1 \mathrm{mg} / \mathrm{kg}$ orally) on net colonic water absorption, orocolonic transit time, and intestinal motility were investigated in pigs chronically fitted either with two cannulas in the proximal colon and a catheter in the duodenum and the ileum or with intraparietal electrodes on the duodenum, jejunum, caecum, and proximal colon and a duodenal catheter. Loperamide, given 20 minutes before a meal reduced significantly colonic net water absorption for 10 hours after eating. It also reduced colonic flow rate, increased orocolonic transit time, modified the postprandial intestinal motility by inducing supplementary phase 3 motor complexes and did not affect caecocolonic motility. Intraduodenal infusion of a hypertonic solution of mannitol (900 mOsm $/ 1 ; 0.6 \mathrm{ml} / \mathrm{minute}$ ) for the first postprandial hour strongly reduced or reversed net colonic water absorption, increased the colonic flow rate, accelerated the orocolonic transit, and induced profuse diarrhoea. After loperamide administration, all these effects were blocked and the relative colonic water absorption, expressed as the fraction of flow entering the colon, was strongly increased. Mannitol did not modify motility of the small and large intestine, and supplementary phase 3 motor complexes were observed when mannitol infusion was preceded by loperamide administration. It is concluded that in experimental osmotic diarrhoea loperamide causes a reduction in digesta flow entering into the colon, mediated by its action on small intestinal motility, and an increase in colonic water absorption.
\end{abstract}

Loperamide, a synthetic opiate derivative, is one of the most commonly used antidiarrhoeal drugs. Its mechanism of action, however, still remains controversial since it may stimulate the rate of absorption by intestinal epithelial cells or modify intestinal motility to slow down the transit of intestinal contents.' Its action on intestinal motility and transit is well documented. In humans, loperamide has been found to stimulate jejunal motility by increasing the frequency of the phase 3 migrating motor complexes ${ }^{2}$ and to delay orocaecal transit time. ${ }^{4}$ Its action on intestinal fluid absorption, however, is not clearly established. In vitro or in anaesthetised animals, loperamide has been found to inhibit intestinal secretion induced by thermostable Escherichia coli, ${ }^{5}$ cholera toxin, ${ }^{6}$ deoxycholic acid, ${ }^{7}$ and prostaglandin ${ }^{89}$ but not by vasoactive intestinal polypeptide or mannitol. ${ }^{8}$
Studies in humans indicate that loperamide does not modify net intestinal or colonic water and electrolyte absorption, ${ }^{210}$ but these were performed in subjects in whom the digestive tract had been emptied of contents and cleansed. We have recently developed a technique in pigs that allows us to determine colonic water absorption in more normal physiological conditions - in the presence of digesta and taking into account the fluctuations associated with eating."

This study aimed to determine in pigs the action of loperamide on colonic water absorption in the presence of faecal material, in basal conditions or during diarrhoea induced by a duodenal infusion of a hypertonic solution of mannitol. Because of differences between species in the effects of loperamide, ${ }^{12}{ }^{13}$ intestinal motility and transit time were monitored to determine whether the stimulation of the migrating motor complexes and the increased transit time found in humans ${ }^{2310}$ is reproduced in pigs.

\section{Methods}

\section{ANIMALS}

Eight large white pigs, each weighing approximately $40 \mathrm{~kg}$ at the beginning of the experiments were studied. The animals were housed in individual cages. They were on a standard diet for growing pigs ( $30 \mathrm{~g} / \mathrm{kg}$ body weight per day) comprising concentrates of barley, wheat, and fish meal (Rental, 31770 Colomiers, France) given twice daily and had free access to water.

Under thiopental anaesthesia, four pigs were fitted with two silicone catheters - one in the lumen of the duodenum $(15 \mathrm{~cm}$ from the pylorus) and one in the ileum $(20 \mathrm{~cm}$ from the ileocaecal junction), and two silicone cannulas (internal diameter $8 \mathrm{~mm}$ ) were inserted in the helicoidal (proximal) colon. The proximal cannula was placed in the first colonic coil $20 \mathrm{~cm}$ from the ileocaecal junction, and the distal cannula, about $50 \mathrm{~cm}$ from the first one in the second coil. The two cannulas and the catheters were brought to the exterior on the left flank.

The remaining four pigs were fitted with an intraduodenal catheter $(15 \mathrm{~cm}$ from the pylorus) and prepared for long term bipolar electromyographic recordings of intestinal motility according to a previously described technique. ${ }^{14}$ Nichrome wire electrodes (Microfil Industrie, Renens, Switzerland) $1 \mathrm{~m}$ in length and $120 \mu \mathrm{m}$ in diameter were implanted in the wall of the jejunum (at 50,150 , and $250 \mathrm{~cm}$ from the ligament of Treitz), the caecum $(10 \mathrm{~cm}$ from the apex), and the proximal colon (in the first and second coil). The free ends of the electrodes and
Correspondence to: Dr J Fioramonti, Department of Pharmacology, INRA, 180 Chemin de Tournefeuille, BP 3, 31931 Toulouse, France. Accepted for publication December 1990 
the catheter were brought to the exterior on the left flank. The animals were allowed to recover for 10 days before beginning the experiments.

\section{NET COLONIC WATER FLUX MEASUREMENT}

Saline solution containing a marker specific for the liquid phase of the digesta, radioactive labelled chromium ethylenediaminetetra-acetic acid $\left({ }^{51}\right.$ Cr-EDTA, Dupont de Nemours, Dreieich, Germany), at a concentration of approximately $0.1 \mu \mathrm{Ci} / \mathrm{ml}$, was continuously infused ( 24 hours/day) at a constant rate of $20 \mathrm{ml} /$ hour through the ileal catheter. Determination of the ${ }^{51} \mathrm{Cr}$-EDTA concentration in colonic samples (about $2 \mathrm{~g}$ ) taken from the two cannulas and in the perfused solution was performed using a $\gamma$ counter (MR $252 \mathrm{C}$, Kontron, Basel, Switzerland). Dry weight of colonic samples was determined by heating about $1 \mathrm{~g}$ at $100^{\circ} \mathrm{C}$ for 24 hours. Net water flux in the colonic segment situated between the two cannulas corresponded to the difference between the flow of the liquid phase of digesta at the level of oral cannula $\left(f_{1}\right)$ and the flow of the liquid phase at the level of the aboral cannula $\left(f_{2}\right)$. Flows were calculated as follows:

$$
\begin{gathered}
\mathrm{f}_{1}=\frac{\mathrm{F}_{\mathrm{o}}\left[\mathrm{C}_{\mathrm{o}}-\left(\mathrm{C}_{1} / \mathrm{q}_{1}\right)\right]}{\mathrm{C}_{1} / \mathrm{q}_{1}} \text { and } \\
\mathrm{f}_{2}=\frac{\mathrm{F}_{\mathrm{o}}\left[\mathrm{C}_{\mathrm{o}}-\left(\mathrm{C}_{2} / \mathrm{q}_{2}\right)\right]}{\mathrm{C}_{2} / \mathrm{q}_{2}}
\end{gathered}
$$

where $F_{o}$ is the rate of ${ }^{51} \mathrm{Cr}$-EDTA infusion, $\mathrm{C}_{\mathrm{o}}$ is the concentration of ${ }^{51} \mathrm{Cr}$-EDTA in the perfused solution, $\mathrm{C}_{1}$ and $\mathrm{C}_{2}$ are the concentrations in the samples taken from the oral $\left(\mathrm{C}_{1}\right)$ and the aboral $\left(C_{2}\right)$ cannulas and $q_{1}$ and $q_{2}$ are the percentages of water in the samples taken from the oral $\left(q_{1}\right)$ and the aboral $\left(\mathrm{q}_{2}\right)$ cannulas.

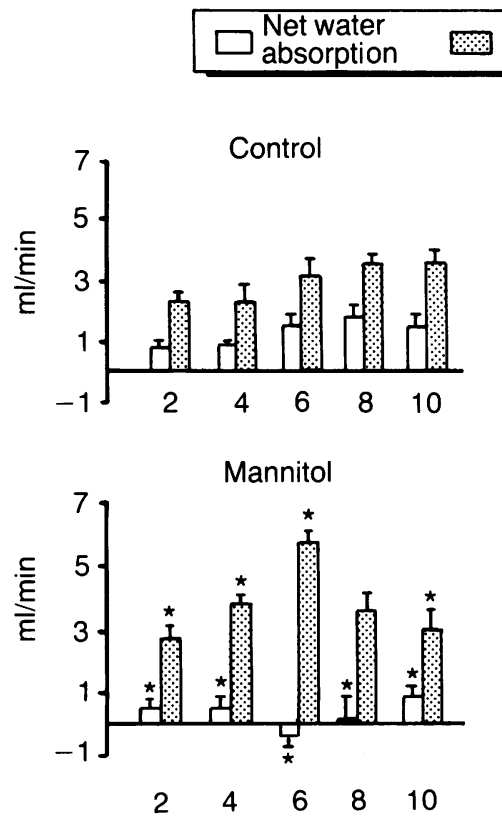

Hours after meal

Figure 1: Postprandial pattern of net water absorption and flow of digesta (liquid phase) in the pig proximal colon (means $(S D), n=8)$. Loperamide $(0 \cdot 1 \mathrm{mg} / \mathrm{kg}$ given orally 20 minutes before the meal) decreased water absorption and digesta flow rate. Mannitol ( $900 \mathrm{mOsm} / \mathrm{l}$ infused intraduodenally at a rate of $6 \mathrm{ml} / \mathrm{minutes}$ for the first postprandial hour) decreased or reversed net water absorption and increased the flow rate. Loperamide given before mannitol attenuated mannitol induced changes but most of the values remained significantly lower than in controls. $\star+$ Significantly different $(p<0 \cdot 05)$ from control $\left({ }^{\star}\right)$ or from mannitol $(t)$ values.
MOUTH TO COLON TRANSIT TIME MEASUREMENT Orocolonic transit time was determined using a rigid probe, $15 \mathrm{~cm}$ long and $6 \mathrm{~mm}$ in diameter, introduced into the colonic lumen through the proximal cannula. At the tip of the probe was a samarium-cobalt magnet (Bregma 17, Arelec, Pau, France) and $2 \mathrm{~mm}$ behind was a magnetic field detector (KMZ 10A RTC, Rhonalco, Toulouse, France). The value of the magnetic field, recorded on a potentiometric recorder (Linear A86, Strasbourg, France) was constant. The animals received $2 \mathrm{~g}$ of iron powder $(40-160$ $\mu \mathrm{m})$ mixed with the morning meal. The passage of iron particles near the probe changed the magnetic field produced by the magnet. Orocolonic transit time was defined as the time elapsing between ingestion of the meal and the first change in the magnetic field detected on the recorder.

\section{MOTILITY RECORDINGS}

The electrical activity of the small and large intestines was recorded with an electroencephalograph (Mini-Huit, Alvar, Montreuil, France) using a short time constant $(0.03$ second $)$ and a paper speed of $2 \cdot 4 \mathrm{~cm} /$ minute. In addition, concurrent summation of the spiking activity from three electrode sites was obtained every 20 seconds by a linear integrator circuit connected to a potentiometric recorder (L 6514, Linseis, Selb, Germany) with a paper speed of $6 \mathrm{~cm} /$ hour.

\section{EXPERIMENTAL PROCEDURE}

In the first group of pigs, orocolonic transit and colonic water absorption were determined by taking samples of contents $(2 \mathrm{~g})$ through the two cannulas at two hourly intervals for 10 hours in each animal. The first sample was obtained two hours after the morning meal (given at $8 \mathrm{am}$ ). In the second group of pigs, direct records of intestinal myoelectrical activity were performed for 10 hours after the morning meal, while the integrated record was continued throughout the day.

Twenty minutes before the morning meal, each animal randomly received placebo or loperamide (Imodium ND, Janssen, Paris) at a dose of $0.1 \mathrm{mg} / \mathrm{kg}$, in a capsule mixed with some grams of food. Placebo and loperamide were given under the same conditions and diarrhoea was induced by an intraduodenal infusion of a hypertonic solution of D-mannitol $(360 \mathrm{ml}, 900$ $\mathrm{mOsm} / \mathrm{l}$ ) during the first postprandial hour. Each experiment was repeated twice in each animal. Experiments in the same animal were performed at minimal intervals of 72 hours. Values were expressed as mean (SD) and comparisons were performed using the Wilcoxon's $t$ test for paired values.

\section{Results}

\section{NET COLONIC WATER ABSORPTION AND flOW} OF DIGESTA

In control studies, two hours after the meal, water was absorbed by the colonic segment between the two cannulas at a rate of $0.83(0.18)$ 


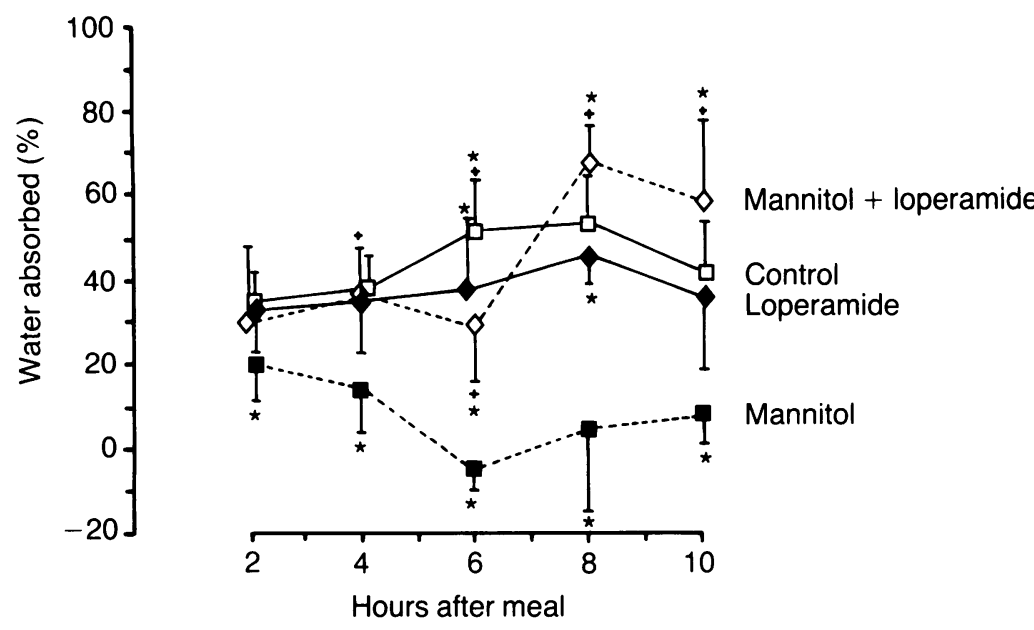

Figure 2: Postprandial changes in relative colonic water absorption expressed as the percentage of water flow entering into the colon (means $(S D), n=8)$. Loperamide $(0 \cdot 1 \mathrm{mg}$ given orally 20 minutes before the meal) slightly but significantly decreased water absorption during the 6th and 8th postprandial hour. Intraduodenal infusion of mannitol strongly decreased or reversed water absorption. This effect was antagonised by loperamide. ${ }^{\star}+$ Significantly different $(p<0.05)$ from control $\left.{ }^{\star}\right)$ or from mannitol $(t)$ values. cantly $(\mathrm{p}<0.05)$ increased compared with values observed after mannitol without loperamide but remained significantly $(\mathrm{p}<0.05)$ lower than control values. The flow of colonic digesta was significantly $(\mathrm{p}<0.05)$ reduced compared with that in pigs given mannitol alone and also compared with controls between hours six and eight (Fig 1). Moreover, the water absorbed, expressed as the percentage of water entering the colonic segment, was significantly $(p<0.05)$ increased in comparison with values observed after the infusion of mannitol alone between hours four and 10 after the meal (Fig 2).

\section{MOUTH TO COLON TRANSIT TIME}

In control studies, orocolonic transit time, determined as the time between ingestion of a meal containing $2 \mathrm{~g}$ of iron powder and the arrival of the first particles of iron at the level of the proximal colonic cannula was $5 \cdot 1(1 \cdot 3)$ hours. Loperamide, administered orally $(0 \cdot 1 \mathrm{mg} / \mathrm{kg}) 20$ minutes before the meal delayed significantly $(p<0.05)$ the orocolonic transit time which reached $10 \cdot 1(0 \cdot 9)$ hours. Intraduodenal infusion of mannitol ( $900 \mathrm{mOsm} / 1,6 \mathrm{ml} /$ minute) during the first postprandial hour induced a significant $(p<0 \cdot 05)$ acceleration of orocolonic transit $(2 \cdot 1$ $(1 \cdot 0)$ hours) but this acceleration was blocked by a previous oral administration of loperamide at a dose of $0 \cdot 1 \mathrm{mg} / \mathrm{kg}$ (Fig. 2). the level of the oral cannula and reached a maximum of $3.54(0.36) \mathrm{ml} /$ minute, eight hours after eating (Fig 1). Similarly, the net relative water absorption increased progressively from $32 \cdot 0(7 \cdot 3) \%$ of the digesta flow during the second postprandial hour to $50.8(11 \cdot 1) \%$ during the eighth hour (Fig 2).

Loperamide, given orally 20 minutes before the meal at a dose of $0 \cdot 1 \mathrm{mg} / \mathrm{kg}$, produced a significant $(p<0.05)$ decrease in the net colonic postprandial water absorption over 10 hours $(0.26(0.20) \mathrm{ml}$ and $0.45(0.18) \mathrm{ml} /$ minute, two and eight hours after the meal respectively). Similarly the flow of digesta at the level of the proximal cannula was significantly $(\mathrm{p}<0.05)$ reduced: $0.90(0.54) \mathrm{ml} /$ minute and $1.04(0.39)$ $\mathrm{ml} /$ minute two and eight hours after eating respectively (Fig 1). In comparison with controls, the relative water absorption, expressed as a percentage of the digesta flow, was significantly $(p<0.05)$ decreased only at six and eight hours (Fig 2).

Intraduodenal infusion of a hypertonic solution of D-mannitol $(900 \mathrm{mOsm} / 1,6 \mathrm{ml} /$ minute) during the first postprandial hour, induced a profuse diarrhoea, beginning four to six hours after starting the infusion. Absolute and relative colonic water absorption were strongly reduced $(0.48(0.25) \mathrm{ml} / \mathrm{minute}, 17.5$ $(8 \cdot 4) \%$, two hours after eating) or reversed to net water secretion $(-0.45(0.24) \mathrm{ml} /$ minute, -8.0 $(4 \cdot 0) \%$, six hours after the meal). At the same time, the flow of digesta was increased, reaching a value of $5.71(0.34) \mathrm{ml} / \mathrm{minutes}$ six hours after the meal, which corresponded to an increase of $79.6 \%$ in comparison with controls.

Oral administration of loperamide $(0 \cdot 1 \mathrm{mg} / \mathrm{kg})$ prevented the diarrhoea induced by the duodenal infusion of mannitol. Values of net water absorption between hours six and 10 were signifi-

\section{SMALL INTESTINE AND COLONIC MOTILITY}

In fasted pigs ( 15 hours after a meal), the myoelectrical activity of the small intestine was organised into migrating myoelectric complexes recurring at 60-90 minute intervals as previously described. ${ }^{15}$ Each migrating myoelectric complex consisted of irregular spiking activity (phase 2) followed by a short (five minute) period of intense and regular activity (phase 3 ). These two period (phase 1) lasting 20-30 minutes. After ingestion of a meal of concentrates $(15 \mathrm{~g} / \mathrm{kg}$ body weight), no phase 3 activity was observed for 174 (37) minutes in the duodenum and 132 (28) minutes in the jejunum. Migrating myoelectric complexes then recurred with a short phase 1 lasting 5-10 minutes.

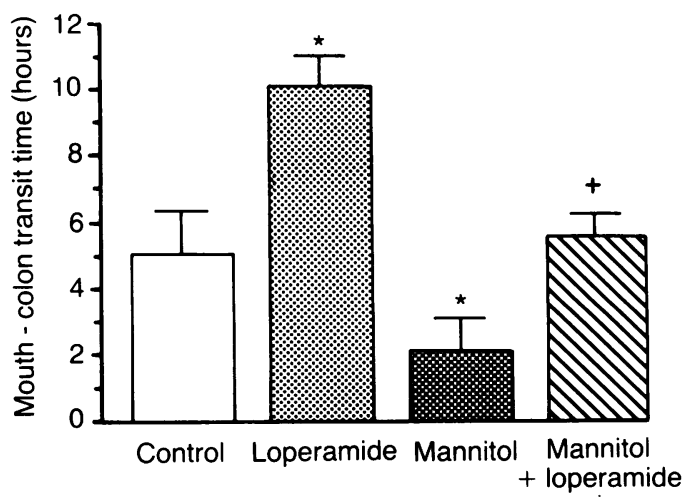

Figure 3: Postprandial mouth to colon transit time (means $(S D), n=8)$. Loperamide $(0 \cdot 1 \mathrm{mg} / \mathrm{kg}$, orally) increased orocolonic transit time, while mannitol $(900 \mathrm{mOsm} / \mathrm{l}$ infused intraduodenally at a rate of $6 \mathrm{ml} /$ minute for 1 hour) accelerated $i$. The effect of mannitol was blocked by previous administration of loperamide. ${ }^{\star}+$ Significantly different $\left(p<0.05\right.$ from control $\left(^{\star}\right)$ or from mannitol $(t)$ values. phases of activity were separated by a quiescent 
Number of small intestinal phase 3 migrating myoelectric motor complexes and colonic phases of contractile activity during a period of 10 hours after a meal (values, means $(S D), n=8$ )

\begin{tabular}{|c|c|c|c|}
\hline & \multicolumn{2}{|c|}{ Intestinal phase 3 activity } & \multirow{2}{*}{$\begin{array}{l}\text { Phases of } \\
\text { colonic motility }\end{array}$} \\
\hline & Duodenum & fejunum & \\
\hline $\begin{array}{l}\text { Control } \\
\text { Loperamide }(0 \cdot 1 \mathrm{mg} / \mathrm{kg} \text { orally }) \\
\text { Mannitol }(900 \mathrm{mOsm} / 1,6 \mathrm{ml} / \mathrm{min}, \text { intraduodenally }) \\
\text { Mannitol after loperamide }(0 \cdot 1 \mathrm{mg} / \mathrm{kg} \text { orally })\end{array}$ & $\begin{array}{l}7 \cdot 7(0 \cdot 5) \\
8 \cdot 6(0 \cdot 6) \\
8 \cdot 1(0 \cdot 5) \\
8 \cdot 8(0 \cdot 5)\end{array}$ & $\begin{array}{c}9 \cdot 2(0 \cdot 5) \\
13 \cdot 1(0 \cdot 6)^{\star} \\
9 \cdot 4(0 \cdot 5) \\
12 \cdot 7(0 \cdot 8)^{\star}\end{array}$ & $\begin{array}{l}84 \cdot 3(7 \cdot 7) \\
88 \cdot 6(8 \cdot 5) \\
90 \cdot 1(8 \cdot 8) \\
86 \cdot 6(7 \cdot 4)\end{array}$ \\
\hline
\end{tabular}

Intraduodenal infusion of mannitol during the first postprandial hour did not change the postprandial pattern of duodenal and jejunal motility (Fig 3, Table). When loperamide was given orally $(0 \cdot 1 \mathrm{mg} / \mathrm{kg}) 20$ minutes before the meal, irrespective of whether or not an intraduodenal infusion of mannitol was given, the number of episodes of phase 3 activity determined for the 10 postprandial hours was significantly increased in the jejunum (Table, Fig 3) and the first phase 3 migrating motor complex occurred sooner after the meal (69 (12) minutes in the duodenum and 59 (9) minutes in the jejunum).

In the caecum and proximal colon; the electrical activity was characterised by long spike bursts grouped in phases lasting three to five minutes and occurring at a frequency of 8.7 $(0 \cdot 7) /$ hour (determined for 10 hours after the morning meal). The frequency and duration of the phases of contractile activity did not change after intraduodenal mannitol infusion or when loperamide was given 20 minutes before a meal whether or not followed by intraduodenal infusion of mannitol (Table).

\section{Discussion}

Our results indicate that in basal conditions
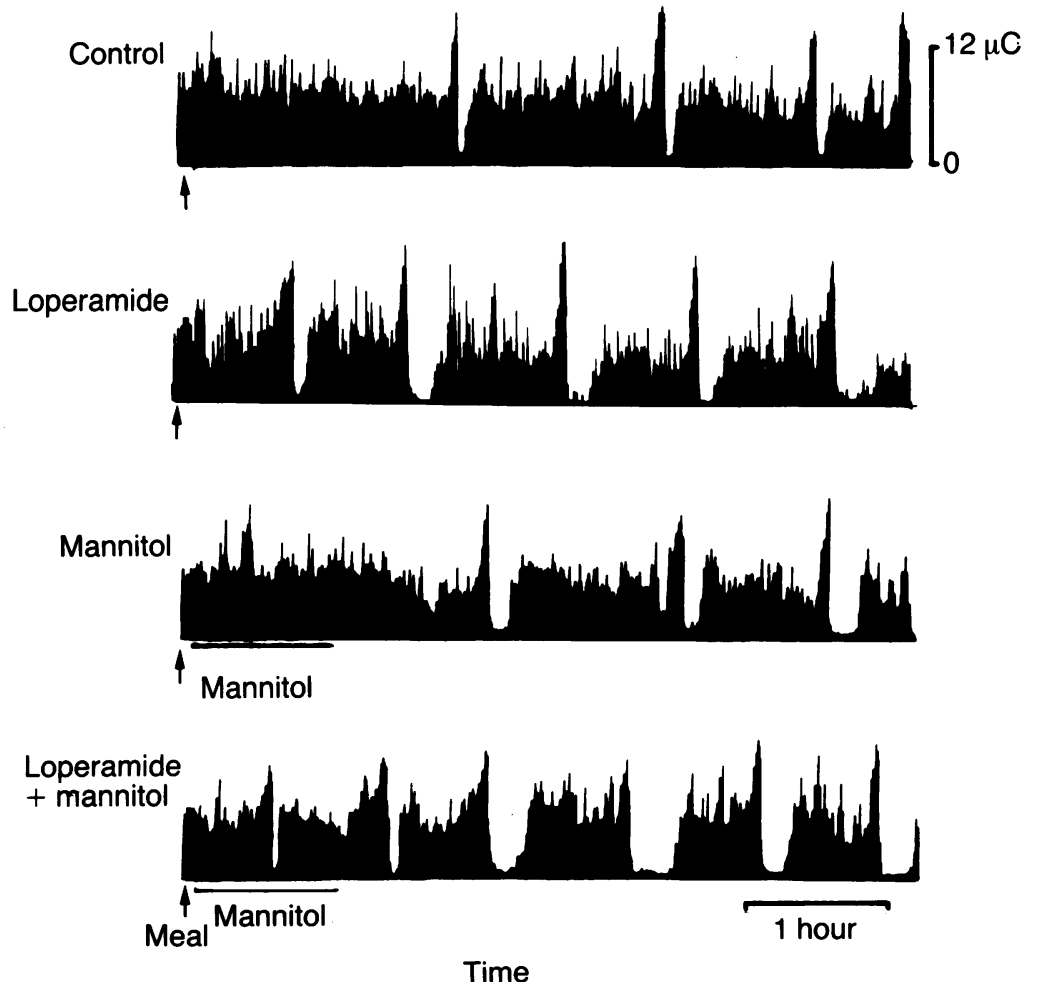

Figure 4: Effect of loperamide on the postprandial pattern of jejunal motility. The records of integrated intestinal myoelectric activity obtained in the same animal indicate that loperamide $(0 \cdot 1 \mathrm{mg} / \mathrm{kg}$ given orally 20 minutes before the meal $)$ increased the number of phase 3 motor complexes after a meal, whether or not followed by an intraduodenal infusion of mannitol (900 $\mathrm{mOsm} / \mathrm{l} 6 \mathrm{ml} / \mathrm{minute}$ ). loperamide reduces the postprandial flow of digesta entering into the colon and the absolute net colonic water absorption, while the relative absorption, expressed as the percentage of digesta flow, remains unchanged or is transiently reduced. During osmotic diarrhoea, loperamide also reduces the flow of digesta but strongly stimulates both absolute and relative colonic water absorption.

The techniques we used for motility studies and colonic water absorption measurements have already been validated. ${ }^{11}$ is The technique for orocolonic transit time measurement has been used for the first time in this study and has not been validated against another technique. In control experiments, however, the arrival of the first iron particles in the colon was detected $5 \cdot 1$ $(1 \cdot 3)$ hours after the meal and this value is within the range of transit time values measured with different liquid or particulate markers. ${ }^{16} 17$

Both in vitro ${ }^{58}$ and in vivo ${ }^{210}$ studies have shown that loperamide did not affect or in some instances stimulate ${ }^{7}$ basal intestinal fluid absorption. Our results show that in basal conditions loperamide paradoxically reduced absolute values of net colonic water absorption. This discrepancy may be the result of different experimental procedures. In studies performed in humans, ${ }^{210}$ the digestive tract was emptied and perfused at a constant rate with a test solution. Our study was performed under more normal physiological conditions since colonic water absorption was determined in animals whose colons contained digesta, and the rate of infusion of the marker into the ileum was negligible in comparison with the rate of flow of digesta. In a previous study" we showed a positive correlation between the net colonic water absorption and the flow of digesta. Indeed, the decrease in absolute water absorption induced by loperamide may be a consequence of the reduction in the flow rate of digesta entering into the colon. This is confirmed by the fact that the relative water absorption, corresponding to the fraction absorbed of the digesta flow, remains unchanged or is slightly decreased.

The decrease in colonic flow rate is in agreement with that observed through the whole digestive tract in humans. ${ }^{10}$ Moreover, our results indicate that this effect is a consequence of the action of loperamide orad to the colon since it increases orocolonic transit time, as already shown in humans. ${ }^{+}$The effects of loperamide on orocolonic transit may be attributed to a decrease in gastric emptying but it has been shown in humans that loperamide does not modify gastric emptying. ${ }^{18}$ This effect is probably the result of an increase in small intestinal transit time as already shown in humans. ${ }^{2} 18$

The main effect of loperamide that we observed on small intestinal motility was the induction of supplementary phase 3 motor complexes as has already been found in humans in both the fasted ${ }^{23}$ and fed states. ${ }^{3}$ This effect of loperamide on the small intestinal motor profile has not been found in other animal species such as the $\operatorname{dog}^{12}$ or the calf ${ }^{13}$ indicating that the pig is an adequate animal model in which to investigate the effects of loperamide. In view of the relations between the flow of digesta and the occurrence of 
migrating myoelectric complexes, ${ }^{19}$ we can speculate that the loperamide induced episodes of phase 3 complexes are responsible for the increase in small intestinal transit time. This hypothesis is reinforced by recent data showing that pharmacological induction of phase 3 motor complexes after a meal strongly reduced intestinal propulsion in rats. ${ }^{20}$ On the other hand, intraduodenal infusion of a hypertonic solution of mannitol increased the colonic rate of flow. Since this increase was reduced by loperamide, which induced intestinal phase 3 motor complexes, the hypothesis that it has a role in blocking phase 3 complexes is supported.

In our study, loperamide had no effect on colonic motility, but long lasting colonic stimulation has been described in dogs. ${ }^{12}$ This corresponds to the large differences between species in the action of opiates on colonic motility. ${ }^{21}$

The mechanism of action of loperamide in health and in diarrhoea is based upon the positive correlation between the flow of colonic digesta and the net colonic water absorption ${ }^{11}$ and upon the theory of Debongnie and Phillips, ${ }^{22}$ which indicates that diarrhoea occurs when the capacity of the colon to absorb fluid is overcome by an input of fluid that is above a critical value. In our experimental model in pigs, loperamide induced phase 3 motor complexes which slowed down intestinal transit, reduced the colonic rate of flow, and consequently reduced absolute net colonic water absorption. Intraduodenal infusion of hypertonic mannitol in pigs increased colonic input above the critical value and led to diarrhoea. This cannot, however, explain by itself the reduction in net water absorption. After mannitol infusion the colonic transit was probably strongly accelerated since diarrhoea occurred four to six hours after the end of infusion while the normal mean retention time of digesta through the pig's colon averages 40 hours. Consequently, as proposed in some diarrhoeal diseases, ${ }^{23}$ too rapid transit does not allow normal absorption of water because the minimum exposure time of the contents to the absorptive surface of the colon is not reached. By slowing down small intestinal transit, loperamide reduced colonic flow, restored normal water absorption, and abolished diarrhoea. After a delay of four hours, however, the relative water absorption, which corresponds to the fraction of the digesta flow absorbed, was strongly increased. This proabsorptive action is in agreement with the efficacy of loperamide in chronic diarrhoea $^{2+}$ which cannot be explained by an action only on motility and transit time.

In conclusion, loperamide abolishes experimental osmotic diarrhoea by acting on small intestinal motility, and consequently reducing the flow entering the colon, and then by stimulating colonic water absorption. Moreover, the pig model can be considered as one of the most suitable for determining human digestive physiology ${ }^{25}$ and should be used to investigate the mechanisms action of other antidiarrhoeal compounds.

We thank G Bories, G Galy, and $R$ Theisen for their skilful technical assistance and $\mathrm{C}$ Jean for typing the manuscript. This work was supported by Institut National de la Récherche Agronomique, Departement de Pathologie Animale.

1 Megens AAHP, Canters LLJ, Awouters FHL, Niemegeer CJE. Is in vivo dissociation between the antipropulsive and antidiarrheal properties of opioids in rats related to gut selectivity? Arch Int Pharmacodyn Ther 1989; 298: 220-9.

2 Kachel G, Ruppin H, Hagel J, Barina W, Meinhardt M, Domschke W. Human intestinal motor activity and transport: effects of a synthetic opiate. Gastroenterology 1986; 90 85-93.

3 Remington M, Malagelada JR, Zinsmeister A, Fleming CR. Abnormalities in gastrointestinal motor activity in patients with short bowels: effects of a synthetic opiate. Gastrowith short bowels: effects
enterology 1983; 85: 629-36.

4 Basilisco G, Bozzani A, Camboni G, et al. Effects of loperamide and naloxone on mouth-to-caecum transit time evaluated by lactulose hydrogen breath test. Gut $1985 ; 26$ $700-3$.

5 Hugues S, Higgs NB, Turnberg LA. Antidiarrhoeal activity of loperamide: studies of its influence on ion transport across rabbit ileal mucosa in vitro. Gut 1982; 23: 974-9.

6 Farack UM, Kautz U, Loeschke K. Loperamide reduces the intestinal secretion but not the mucosal cAMP accumulation intestinal secretion but not the mucosal cAMP accumulation induced by cholera toxin.
Pharmacol $1981 ; 317: 178-9$.

7 Farack UM, Loeschke K. Inhibition by loperamide of deoxycholic acid induced intestinal secretion. Naunyn Schmiedebergs Arch Pharmacol 1984; 325: 286-9.

8 Beubler E, Lembeck F. Inhibition of stimulated fluid secretion in the rat small and large intestine by opiate agonists. Naunyn Schmiedebergs Arch Pharmacol 1979; 306 113-8.

9 Hardcastle J, Hardcastle PT, Read NW, Redfern JS. The action of loperamide in inhibiting prostaglandin-induced intestinal secretion in the rat. Br f Pharmacol 1981; 74: intestinal

10 Schiller LR, Santa Ana C, Morawski SG, Fordtran JS Mechanism of the antidiarrheal effect of loperamide. GastroMechanism of the antidiarrheal
enterology $1984 ; 86: 1475-80$.

11 Theodorou V, Fioramonti J, Buéno L. Water absorption from the pig proximal colon: relations with feeding and flow of digesta. Qf Exp Physiol 1989; 74: 521-9.

12 Fioramonti J, Fargeas MJ, Buéno L. Stimulation of gastrointestinal motility by loperamide in dogs. Dig Dis Sci 1987 32: 641-6.

13 Fioramonti J, Buéno L. Effects of loperamide hydrochloride on experimental diarrhoea and gastrointestinal myoelectrical activity in calves. Am $\mathcal{F}$ Vet Res $1987 ; 48: 415-9$.

14 Ruckebusch Y. The electrical activity of the digestive tract of the sheep as an indication of the mechanical events in various regions. F Physiol 1970; 210: 857-82.

15 Ruckebusch Y, Buéno L. The effect of feeding on the motility of the stomach and small intestine in the pig. Brf Nutr 1976 35: 397-405.

16 Ishikawa S, Sugimura K. Movement of polyvinylalcohol through the digestive tract as a digestion indicator with swine. Agricultural and Biological Chemistry 1973; 37: 203-6.

17 Clemens ET, Stevens CE, Southworth M. Sites of organic acid production and pattern of digesta movement in the gastroproduction and pattern of digesta movement in the

18 Sninsky CA, Davis RH, Clench MH, Thomas KT, Mathias JR. Effect of lidamidine hydrochloride and loperamide on gastric emptying and transit of the small intestine. A doublegastric emptying and transit of the small intesting
blind study. Gastroenterology 1986; 90: 68-73.

19 Buéno L, Fioramonti J, Ruckebusch Y. Rate of flow of digesta and electrical activity of the small intestine in dogs and sheep. F Physiol 1975; 249: 69-85.

20 Fargeas MJ, Fioramonti J, Buéno L. Central and peripheral actions of adenosine and its analogues on intestinal myoelectric activity and propulsion in rats. $\mathcal{7}$ Gastrointest Motility 1990; 2: 121-7.

21 Fioramonti J, Niemegeers CJ, Awouters F. Diarrhea and antidiarrheal drugs. In: Ruckebusch Y, Toutain PL, Koritz GD, eds. Veterinary pharmacology and toxicology. Lancaster: MTP Press, 1983: 283-98.

22 Debongnie JC, Phillips SF Capacity of the human colon to absorb fluid. Gastroenterology 1978; 74: 698-703.

23 Read NW, Miles CA, Fisher D, et al. Transit of a meal through the stomach, small intestine, and colon in normal subjects and its role in pathogenesis of diarrhea. Gastroenterology 1980; 79: 1276-82.

24 Pelemans W, Vantrappen G. A double blind crossover comparison of loperamide with diphenoxylate in the symptomatic treatment of chronic diarrhea. Gastroenterology 1976; 70: $1030-4$.

25 Miller ER, Ullrey DE. The pig as a model for human nutrition. Annu Rev Nutr 1987; 7: 361-82 